\title{
"Ladrão se mata com tiro": lírica e autoritarismo em "Morte do leiteiro" de Carlos Drummond de Andrade.
}

* Professor de Teoria Literária na UNEB-Brumado-BA e doutorando em Literatura Brasileira (FFLCH-USP).
' FERNANDES, Florestan. Mudanças sociais no Brasil: aspectos do desenvolvimento da sociedade brasileira. São Paulo: Difusão Européia do Livro, [1960].
'MILLIET, Sérgio. Diário critico de Sérgio Milliet. São Paulo: Martins/Edusp, 1981, 2. ed., vol. III, p. 19 e ss.

\author{
Cristiano Augusto da Silva Jutgla*
}

\section{Resumo}

0 objetivo deste artigo é tecer algumas considerações críticas a respeito das configurações entre sujeito lírico e autoritarismo no poema "Morte do leiteiro", de Carlos Drummond de Andrade, da obra A rosa do povo, de 1945.

Palavras-chave: Drummond, lírica, autoritarismo, poesia brasileira.

M inha análise de "Morte do leiteiro", de Carlos Drummond de Andrade, centra-se na tensão interna do poema que, construído sobre uma narrativa de conteúdo violento, se configura por meio da alegoria, em um discurso de resistência ao processo de "modernização conservadora" brasileira dos anos 30 e 40, bem como ao Estado Novo, marcado por seu projeto totalizante de nação homogênea.

Devido à proximidade da lírica drummondiana de 45 ao pensamento da Escola de Frankfurt, o trabalho terá como apoio teórico as reflexóes de Theodor Adorno e Walter Benjamin.

Ao longo de seus sessenta anos (comemorados recentemente em 2005), esta obra central de Drummond consagrou-se como uma das principais da poesia brasileira. Uma das razóes para tamanho reconhecimento seja talvez, dentre outros motivos, a tensa configuração de seus versos com questôes de seu tempo, em especial com a história brasileira e européia, aspecto este apontado em sua fortuna crítica de maneira reiterada. Só para tomarmos dois exemplos, cito o texto de Sérgio Milliet, que já em 1945 assim a receberia: "A quem acompanha com carinho e fé a evoluçáo poética de Carlos Drummond de Andrade, seu livro $A$ rosa do povo traz uma sensação de euforia.(..) Sua poesia, hoje madura e nobre, perdeu aquela graça leve da primeira fase para adquirir uma beleza mais serena, um equilíbrio que tira sua solidez da verticalidade de suas raízes." 
Antonio Candido, em 1965, ressaltaria a importância da matéria histórica no livro, compreendendo que a tematização dos conflitos sociais e políticos em $A$ rosa do povo é resultado de um processo na poesia drummondiana que já se iniciara em meados dos anos 30: "Essa função redentora da poesia, associada a uma concepção socialista, ocorre em sua obra a partir de 1935 e avulta a partir de 1942, como participação e empenho político. Era o tempo da luta contra o fascismo, da guerra de Espanha e, a seguir, da Guerra Mundial - conjunto de circunstâncias que favoreceram em todo o mundo o incremento da literatura participante." 3

Outros críticos, nas décadas seguintes, apontariam também esta característica como cerne da obra de 1945; citamos apenas alguns rapidamente: Merquior $(1965)^{4}$, Simon (1978) , Gledson $(1980)^{6}$, Arrigucci Jr. $(2000)^{7}$. Em suas relações com o autoritarismo, percebemos basicamente dois movimentos reflexivos do sujeito lírico: o primeiro, mais explícito nos conteúdos de alguns poemas, é a tentativa de o sujeito lírico dialogar com questōes prementes de seu contexto histórico, alçadas à esfera pública brasileira, como a Segunda Guerra Mundial, o nazismo e o fascismo. Exemplo desta tematização histórica aparece no poema "Nosso tempo" em que se observa uma reflexão agônica da condição dos seres humanos, leitura que vai em sentido radicalmente diverso ao do discurso progressista e ufanista do tempo na Era Vargas: "Este é tempo de partido,/ tempo de homens partidos.// Em vão percorremos volumes,/ viajamos e nos colorimos./ A hora pressentida esmigalha-se em pó na rua./ Os homens pedem carne. Fogo. Sapatos./ As leis não bastam. Os lírios não nascem/ da lei. Meu nome é tumulto, e escreve-se/ na pedra."

O poema se constrói sobre imagens que constituem um pólo negativo e portanto crítico à ideologia capitalista, apontando uma vida social marcada por impasses, fissuras sociais e individuais, divisão de classes, heterogeneidade tensa. Em "Carta a Stalingrado", temos outro exemplo de tematização da história; a participação do sujeito lírico é elaborada através de um diálogo elegíaco à cidade russa que resiste à invasão alemã durante a Segunda Guerra Mundial: "Stalingrado.../ Depois de Madri e de Londres, ainda há grandes cidades!/ O mundo não acabou, pois que entre as ruínas/ outros homens surgem, a face negra de pó e de pólvora,/ e o hálito selvagem da liberdade/ dilata os seus peitos, Stalingrado,/ seus peitos que estalam e caem/enquanto outros, vingadores, se elevam."

Suas referências ao contexto de produção estão não apenas no título, mas também no diálogo que o sujeito lírico instaura com Stalingrado, destinatária e interlocutora de sua mensagem. ${ }^{8}$ Curiosamente, apesar de nas últimas décadas os estudiosos de Drummond terem ressaltado o problema da história em $A$ rosa do povo, suas reflexões voltam-se quase sempre sobre determinados poemas, enquanto outros, tidos como menos "engajados", não foram objeto de estudos mais detidos. Um exemplo desta pouca atenção a poemas "menos participantes" aparece nas palavras de Vagner Camilo que, valendose de clássico ensaio de Antonio Candido", notará em "Morte do leiteiro" um "gosto pela notação quotidiana, despida, é certo, de todo pitoresco e anedótico, que constitui, como assinala Antonio Candido, uma forma bastante "peculiar" da poesia social de Drummond (...)."10
${ }^{3}$ CANDIDO, Antonio.

"Inquietudes na poesia de Drummond". In: Vários escritos. 3. ed. São Paulo: Duas Cidades. 1995. p. 125.

${ }^{4}$ Merquior, J. G. Razão do poema: ensaios de crítica e estética. 2. ed. Rio de Janeiro: Toopbooks, 1996. p.100.

'SIMON, Iumna Maria. Drummond: uma poética do risco. São Paulo: Ática. 1978. pp. 52-3.

${ }^{6}$ GLEDSON, John. Poesia e poética de Carlos Drummond de Andrade. São Paulo: Duas Cidades, 1981, p. 163.

${ }^{7}$ Arrigucci Jr., Davi. Coração partido - uma análise da poesia reflexiva de Drummond. São Paulo: Cosac \& Naify, 2002, pp. 102-3.

${ }^{8} \mathrm{Cf}$. a interessante e produtiva análise de Simon sobre este e outros poemas cuja temática histórica aparece de maneira explícita. In: Drummond: uma poética do risco. São Paulo: Ática, 1978. pp. 89-102.

${ }^{9}$ CANDIDO, Antonio. "Inquietudes na poesia de Drummond", op. cit. ${ }^{10}$ CAMILO, Vagner.

Drummond: da rosa do povo à rosa das trevas. Cotia: Ateliê Editorial, 2000, p. 106. 
"ANDRADE, Carlos Drummond de. $A$ rosa do povo. 10 ed. Rio de Janeiro: Record, 1991.
Apesar da complexidade do poema, este caráter de comentário breve de "Morte do leiteiro" tem curiosamente prevalecido para alguns poemas de $A$ rosa do povo. Na maioria das vezes, a crítica tem dado pouca atenção às análises e interpretações, prevalecendo uma certa totemização para com as leituras clássicas de Drummond, como se outras possibilidades não fossem possíveis de enriquecer o debate. Ora, é de se estranhar, pensando-se no contexto de produção de $A$ rosa do povo (Estado Novo, ascensão do nazifascismo, Segunda Guerra, capitalismo industrial no Brasil), certos poemas serem preteridos por boa parte da crítica, uma vez que pertencem a um conjunto, "a um todo coerente e coeso de significado" (para lembrarmos uma clássica definição lingüística para texto). Em outras palavras, é no "peculiar" apontado por Antonio Candido que procuro trilhar um caminho analítico de "Morte do leiteiro". Composto por oito estrofes com versos ritmados, quase todos octossílabos, o poema narra a história de um moço, leiteiro, que entrega diariamente "leite bom, para gente ruim" e que, 'confundido' com um bandido, é morto por um senhor assustado com a onda de assaltos no bairro em que mora. $\mathrm{O}$ poema inicia-se por uma estrofe que desempenha uma espécie de preâmbulo de teor moral acerca da história que será narrada. Vejamos seus primeiros seis versos, todos assertivos: "Há pouco leite no país,/é preciso entregá-lo cedo./ Há muita sede no país,/ é preciso entregá-lo cedo./ Há no país uma legenda, que ladrão se mata com tiro."1

Temos uma construção paralelística, três versos iniciados com o verbo haver no presente com respectivos advérbios 'pouco' e 'muito', complementos verbais e adjuntos adverbiais de lugar, seguidos da necessidade de açōes: "há pouco leite no país, é preciso entregá-lo cedo,/ há muito leite no país, é preciso entregá-lo cedo." O sujeito lírico lança, já na abertura do poema, uma situação inusitada entre os quatro primeiros versos com seus advérbios e ações imperativas ('pouco leite' x 'muita sede' >> é preciso entregá-lo cedo) e os dois últimos versos (Há no país uma legenda,/que ladrão se mata com tiro.); e, como toda lenda, se apresenta como uma concretização histórica do imaginário e, por conseguinte, do conjunto de valores, crenças e práticas de determinado grupo social. Até aqui, parece não haver nada de estranho não fossem os dois últimos versos que, de maneira próxima a uma parábola, trazem um conteúdo moralizante. Há poucos detalhes e o mais importante é a mensagem: "Há no país uma legenda,/ ladrão se mata com tiro".

Ora, a ausência de detalhes se deve não apenas por se tratar de um poema, com sua linguagem sintética, mas por uma estratégia de silenciamento que, de maneira alegórica conta muito, dizendo pouco, ampliando seu alcance crítico sem ser notado pela censura de seu contexto de produçáo. Veremos que na segunda estrofe os versos dois, três, quatro e cinco centram-se na configuração de seu personagem principal, ou melhor, na divisão de classes e no sistema de produção em que este moço está inserido: "(...) alguém acordou cedinhol e veio do último subúrbiol trazer o leite mais friol e mais alvo da melhor vacal para todos criarem força/ na luta brava da cidade". Ainda na referida estrofe há uma sinédoque; seus instrumentos de trabalho avisam "aos homens no sono/ que "alguém acordou cedinho" para lhes trazer leite "mais frio da melhor vaca". 
$\mathrm{Na}$ terceira estrofe, temos indicaçōes de seu trabalho cansativo e de uma contradição explícita: "sai correndo e distribuindo/ leite bom para gente ruim". Trata-se de uma imagem que, como na estrofe inicial, aponta o paradoxo do leite, metáfora tradicionalmente positiva (pureza, vitalidade, maternidade, crescimento), e o caráter negativo das pessoas que o recebem, mostrado cruamente pelo adjetivo "ruim". Notemos que a sinédoque dos instrumentos de trabalho do leiteiro transforma-se em um corte na descrição do leiteiro, corte este feito pela pressa imposta pelo tempo capitalista. O próprio sujeito lírico mostra que "sequer a garrafa" (um objeto, portanto) não tem tempo de dizer ao leiteiro suas qualidades: " $\mathrm{Na}$ mão a garrafa brancal não tem tempo de dizerl as coisas que lhe atribuo."

Se na segunda estrofe as pessoas ouviam o som de "sua lata, suas garrafas/e seus sapatos de borracha", na terceira estrofe os produtos se personificam e o leiteiro se coisifica, pois nem ao menos a garrafa tem tempo de dizer suas qualidades. Além disso, a própria condição do leiteiro não consegue estabelecer um diálogo com o sujeito lírico, ou seja, não há possibilidade de comunicação, ou aproximação entre ambos: "nem o moço ignaro,/ morador na Rua Namur,/ empregado no entreposto,/ com 21 anos de idade,/ sabe lá o que seja impulso/ de humana compreensāo."

Ao dizer que o leiteiro não sabe o que seja "impulso de humana compreensão", o sujeito lírico lança uma terceira tensão: o desconhecimento de si mesmo. Tal situação guarda nítida semelhança com pontos centrais da Crítica à Economia Política marxista. É preciso pensar que a alienação, tal como Marx tratou, se concretiza no momento em que o ser humano deixa de reconhecer sentido ou função no produto de seu trabalho. Assim, o que é feito pelo ser humano, realizado para responder às necessidades vitais de sua sobrevivência, deixa no âmbito do capitalismo de ser reconhecido como tal. O resultado do trabalho humano transforma-se em algo estranho a seu próprio criador, uma vez que se produzem coisas sem necessidade intrínseca de uso e não se conhecem mais todas as etapas de produção. Por seu trabalho alienado o ser humano receberá um valor em dinheiro que sequer minimamente guardará relação com seu real valor de venda. Estamos, portanto, no mundo do fetiche da mercadoria e da reificação humana. Reparemos nos versos finais da terceira estrofe, em especial, nos dois últimos: "E já que tem pressa, o corpo/ vai deixando à beira das casas/ uma apenas mercadoria". Nosso protagonista é comandado pela mercadoria.e não tem consciência de sua condição, transformando-se em um autômato como demonstra a imagem do corpo, em vez de um ser, que deixa "à beira das casas uma apenas mercadoria." Na quinta estrofe, encontramos imagens relativas a espaços que configuram, em perspectiva alegórica, o grau de divisão de classes e opressão: "E como a porta dos fundos/ também escondesse gentel que aspira ao pouco de leitel disponivel em nosso tempo,l avancemos por esse beco, / peguemos o corredor, / depositemos o litro.../ Sem fazer barulho, é claro,/ que barulho nada resolve."

A imagem da "porta dos fundos" que "esconde" gente nos dois primeiros versos é bastante forte, principalmente quando, mais adiante, este grupo excluído for atacado pelo senhor que, preocupado com os ladrōes que "infestam" o bairro, matará um "inocente" para salvar sua propriedade. Vale 
notar também que o leite, aspirado por todos "em nosso tempo", é "pouco"; tal situação foi apontada logo na primeira estrofe, fato que, diante da "muita sede no país", cria uma tensão novamente presente na quinta estrofe, tensão esta que não só vem se processando desde os primeiros versos como alcançará seu clímax a partir da quarta estrofe: "Meu leiteiro tão sutil/ de passo maneiro e level antes desliza que marcha./ E certo que algum rumor/ sempre faz: passo errado,/vaso no caminho,/ cão latindo por princípio, ou um gato quizilento/. E há sempre um senhor que acorda,/ resmunga e torna a dormir."

A narrativa prossegue com o jovem trabalhador entregando seu leite. Nos três primeiros versos o sujeito lírico novamente expressa, por meio do elogio, uma identificação afetiva com o leiteiro, mostrando ainda seus percalços diários. Contudo, será nos dois últimos versos desta quinta estrofe, de conteúdo aparentemente banal, que a tensão maior da narrativa se põe em marcha, ligando-se diretamente à sexta estrofe:

\author{
E há sempre um senhor que acorda, \\ resmunga e torna a dormir. \\ Mas este entrou em pânico \\ (ladrōes infestam o bairro), \\ não quis saber de mais nada. \\ O revólver da gaveta \\ saltou para sua mão. \\ Ladrão? se pega com tiro. \\ Os tiros na madrugada \\ liquidaram meu leiteiro.
}

"Nāo quis saber de mais nada", com este verso o destino do leiteiro é selado. Ou seja, seu pânico faz com que este senhor concretize a violência do sistema no qual está inserido por meio do assassinato de outro ser humano. Seu medo, seu pânico de perder mercadorias (sua propriedade) faz dele um autômato. Somente após matar o leiteiro que o homem se dá conta de seu ato: "Meu Deus, matei um inocente." Outra vez, em seguida, há mais uma legenda, posta sorrateiramente pelo sujeito lírico na boca do senhor: "Bala que mata gatuno/ também serve pra furtar/ a vida de nosso irmão./ Quem quiser que chame médicol policia não bota a mãol neste filho de meu pai."

A (aparente) preocupação (?!?) do senhor, contudo, se mostra periclitante pelo verso seguinte, indicando uma constituição ética no tocante ao direito à vida de outra pessoa, orientada por valores que muito lembram o fetiche da mercadoria discutido por Marx; tanto assim que o autor dos disparos isenta-se até mesmo de chamar um "médico". Traços de arrogância, prepotência e cinismo estão mais do que explícitos nestes três curtos versos: "Quem quiser que chame médico/ polícia não bota a mão/ neste filho de meu pai./ Está salva a propriedade."

"Está salva a propriedade", quem diz esta frase? O sujeito lírico ou o homem que matou o leiteiro? Nāo é possível saber graficamente quem a 
profere, o poema não traz sinais gráficos que indiquem com certeza quem a proferiu, se um, se outro. Fica a ambigüidade em nada gratuita no momento de maior tensão da narrativa. Vejamos por quê. Se o senhor tiver dito a frase, justifica-se, no âmbito do capitalismo, a ação de matar um suspeito de atentar contra a propriedade; fecha-se, assim, o ciclo de violência sobre os pobres (pouco leite x muita sede/ leite bom x para gente ruim). Se o narrador tiver dito a frase, entreabre-se então uma situação mais terrível ainda quanto ao autoritarismo praticado por aquele que defende sua propriedade: "Quem quiser que chame médico/ polícia não bota a mão/ neste filho de meu pai". Estes três versos demonstram o poder acima de qualquer lei ou força do Estado de Direito; se a polícia não bota a mão "neste filho de meu pai", quem ousaria colocar?12 O "senhor assustado" não só se arroga acima de qualquer regra, como já colocara em prática seu poder ao assassinar o leiteiro. Aparentemente, poder-se-ia afirmar que ele vive dentro da mais absoluta desobediência civil, que não reconhece sequer a autoridade policial; em teoria, sim, ele seria um 'perigo' para a sociedade. Contudo, se pensarmos que, no contexto da história brasileira o direito (de proteção à propriedade, sobretudo) sempre existiu em benefício de pequenos grupos econômicos e políticos, sobrando a aplicação da lei penal para a maioria, então veremos que não, que o senhor que mata o leiteiro nada faz do que renovar o pacto outorgado pelos grupos dominantes política e economicamente, isto é, a lei, o castigo, as penas servem ao grosso da população; o direito, as salvaguardas, a liberdade servem ao 'seleto' grupo dos proprietários do capital, bem como suas camadas médias e (por que não dizer?) medíocres. Fazendo-se uma breve aproximação com a obra clássica de Michel Foucault, Vigiar e punir, veremos que, concomitante à passagem do Antigo Regime, aristocrático, para o Estado burguês, liberal e capitalista, se processou uma mudança em todo o sistema penal na França, ou seja, nas concepções de crime bem como nas penas que está diretamente ligada a transformaçôes no campo da economia política não só daquele país, mas em outros como a Inglaterra. Assim, em um primeiro momento (sobretudo nos séculos XVI e XVII), o castigo corporal incluída a morte do condenado era um evento público; deixar as marcas no corpo, fazer o culpado sofrer fisicamente tanto ou mais do que causara à vítima era a própria concretização do poder do Rei. A partir da Revolução Francesa, a idéia é preservar sua vida e, obviamente, o corpo do culpado, retirá-lo da esfera pública e aplicar-lhe um castigo de longa duração, a fim de que sua pena servisse como exemplo aos que pensassem em seguir futuramente os passos do culpado, o qual passa a potencial 'trabalhador' ou 'escravo' a serviço da sociedade; houve, portanto, uma espécie de abrandamento das penas no tocante a práticas de tortura física no início do século XIX. Interessante pensar que a passagem do Antigo Regime para o Estado burguês se configura na passagem da repressão, por parte das autoridades criminais, aos que atentavam contra a vida, no período monárquico, aos que passam a atentar contra a propriedade, no período capitalista. ${ }^{13} \mathrm{O}$ que nos surpreende ao pensarmos as questōes lançadas em "Morte do leiteiro" é a perspectiva reveladora de uma relação de forças que foge à análise de Foucault, o que demonstra que sequer um Estado burguês se configurou no Brasil, o que em si necessa-
${ }^{12}$ A leitura deste verso, "neste filho de meu pai", como uma referência direta do 'senhor' não ao leiteiro estatelado no chão, mas a si próprio, me foi apontada argutamente por uma aluna do curso de Letras da UEFS, Jecilmar, a quem agradeço enormemente. Tratase, segundo a colaboradora, de uma expressão comum em regiões interioranas. Tal colaboração ocorreu durante apresentação deste texto em comunicação realizada no I Seminário Internacional de Teoria e História Literárias (SETHIL), ocorrido na UESB, em Vitória da Conquista, de 8 a 11 de outubro de 2005.

${ }^{13}$ Afirma Foucault: "Quer dizer que se, aparentemente, a nova legislação criminal se caracteriza por uma suavização das penas (...), ela é apoiada basicamente por uma profunda alteração na economia tradicional das ilegalidades e uma rigorosa coerção para manter setı ajustamento. Um sistema penal deve ser concebido como um instrumento para gerir diferencialmente as ilegalidades, não para suprimi-las a todas." Idem, p. 75. (grifo meu). 
14 "É necessário là época da reforma penal na França] um código exaustivo e explícito, que defina os crimes, fixando as penas. Mas o mesmo imperativo 'de cobertura integral pelos efeitos-sinais da punição obriga a ir mais longe. A idéia de um mesmo castigo não tem a mesma força para todo mundo; a multa não é temivel para 0 rico, nem a infâmia a quem já está exposto." Idem, pp. 82-3.

${ }^{15}$ BOBBIO, Norberto et. alii. Dicionário de política. 7. ed. Brasilia: UNB, 1995. vol.1, pp. 100-1. (grifos meus) riamente não significaria uma qualidade no tocante às relaçóes econômicas e políticas, mas, penso, sobretudo, na questão do acesso mínimo ao direito e às leis e, por conseguinte, em uma sociedade baseada em relaçóes norteadas por princípios de equanimidade, não de estratificação de classe. $O$ pensador francês chama-nos a atenção para o fato de que o burguês ou um nobre também estavam sujeitos à lei, sendo crimes praticados por tais classes mais impactantes ao conjunto social do que por uma 'pessoa do povo'. ${ }^{14}$ No contexto de nosso poema, o burguês, o proprietário está fora de qualquer chance de ser enquadrado legalmente por seu crime. Ora, náo vejo tal poder senão como a açáo concreta do poder de grupos dominantes sobre a maioria da população. Noto também nessa imunidade dada por sua condição econômica e social um movimento rumo não apenas ao autoritarismo, mas sim ao totalitarismo, uma vez que qualquer outra instância divergente de sua concepção, qualquer 'suspeito' deve ser subjugado, como afirma Stoppino. ${ }^{15}$ A estrofe final é, a meu ver, a mais instigante, dado que dos destroços "mal redimidos da noite", enfim, desta violência entre forças desiguais, há um movimento de resistência da vida:

Da garrafá estilhaçada,
no ladrilho já sereno
escorre uma coisa espessa
que é leite, sangue... não sei.
Por entre objetos confusos,
mal redimidos da noite,
duas cores se procuram,
suavemente se tocam,
amorosamente se enlaçam,
formando um terceiro tom
a que chamamos aurora.

Nos seis primeiros versos da estrofe final, o sujeito lírico se mostra vacilante frente a tal situação; sua segurança ao narrar, demonstrada até a penúltima estrofe, torna-se fragmentária, inconstante, como demonstram as expressões: "estilhaçada", "confusos", "mal redimidos", "não sei". Nos cinco últimos versos, o movimento de procura de duas cores com seu toque suave, seu enlaçamento amoroso criam uma outra perspectiva que, por sua sutileza, vai em caminho radicalmente diverso ao de toda a narrativa tensa e violenta que se processou anteriormente. É justamente esta sutileza e beleza presentes na aurora que causam um choque no leitor, que chamam sua atenção para um mundo que nos é vendido como homogêneo e justo. Na situação "peculiar" (pressentida, mas não desenvolvida por Candido) de um jovem explorado, que traz 'leite bom para gente ruim', situa-se e concretiza-se toda a contradição fundamental da dinâmica de exploração capitalista no Brasil: eu te exploro e você me serve em silêncio, eu te mato e não pago nenhum preço por isso. Assim, concluo, retomando os versos inicias do poema: "Há o pouco leite no país" poderia, dentre diversas significaçōes, ser o direito ao estatuto de dignidade humana proibido à maioria das pessoas no sistema capitalista. Já o verso "Há muita 
sede no país" se apresenta como seu oposto, ou seja, o estatuto humano reservado a poucos (precário também, posto que assentado em opressão ao outro); sede que, em uma sociedade conservadora, só pode ser saciada por uma minoria que, para tanto, vale-se da violência. Dizer que "ladrão se pega com tiro" faz, nesse jogo de cartas marcadas, todo o sentido e justifica a morte de milhóes e milhões de leiteiros cotidianamente, seja no Brasil dos anos 30 e 40, seja no Brasil atual.

\section{Abstract}

This essay will make critical considerations about the configurations between the lyrical subject and authoritarianism in the poem "Morte do leiteiro" by Carlos Drummond de Andrade, present in the book A rosa do povo (1945).

Keywords: Drummond, lyric, authoritarianism, brazilian poetry.

0 artigo está diretamente relacionado à minha tese de doutorado, em andamento. Sua produção tem origem em uma comunicação realizada no I Seminário Internacional de Teoria e História Literárias (SETHIL), ocorrido na UESB, em Vitória da Conquista - BA, de 8 a 11 de outubro de 2005. 